\title{
Enriching Glucoraphanin in Brassica rapa Through Replacement of BrAOP2.2/BrAOP2.3 with Non-functional Genes
}

\section{OPEN ACCESS}

Edited by:

Maoteng Li,

Huazhong University of Science and

Technology, China

Reviewed by:

Zhongyun Piao,

Shenyang Agricultural University,

China

Qing-Yong Yang,

Huazhong Agricultural University,

China

${ }^{*}$ Correspondence:

Xiaowu Wang

wangxiaowu@caas.cn

${ }^{\dagger}$ These authors have contributed equally to this work.

Specialty section

This article was submitted to Crop Science and Horticulture, a section of the journal

Frontiers in Plant Science

Received: 02 May 2017

Accepted: 17 July 2017

Published: 02 August 2017

Citation:

Liu Z, Liang J, Zheng S, Zhang J, Wu J, Cheng $F$, Yang $W$ and Wang $X$

(2017) Enriching Glucoraphanin in

Brassica rapa Through Replacement

of BrAOP2.2/BrAOP2.3 with

Non-functional Genes.

Front. Plant Sci. 8:1329.

doi: 10.3389/fp/s.2017.01329

\section{Zhiyuan Liu ${ }^{1,2+}$, Jianli Liang ${ }^{1+}$, Shuning Zheng ${ }^{1}$, Jifang Zhang ${ }^{1}$, Jian $W u^{1}$, Feng Cheng ${ }^{1}$, Wencai Yang ${ }^{2}$ and Xiaowu Wang ${ }^{1 *}$}

${ }^{1}$ Institute of Vegetables and Flowers, Chinese Academy of Agricultural Sciences, Beijing, China, ${ }^{2}$ College of Horticulture, China Agricultural University, Beijing, China

Sulforaphane, the hydrolytic product of glucoraphanin glucosinolate, is a potent anticarcinogen that reduces the risk of several human cancers. However, in most $B$. rapa vegetables, glucoraphanin is undetectable or only present in trace amounts, since the glucoraphanin that is present is converted to gluconapin by three functional BrAOP2 genes. In this study, to enrich beneficial glucoraphanin content in $B$. rapa, the functional BrAOP2 alleles were replaced by non-functional counterparts through marker-assisted backcrossing (MAB). We identified non-functional mutations of two BrAOP2 genes from B. rapa. The backcross progenies with introgression of both non-functional braop2.2 and braop2.3 alleles significantly increased the glucoraphanin content by 18 times relative to the recurrent parent. In contrast, replacement or introgression of single non-functional braop2.2 or braop2.3 locus did not change glucoraphanin content. Our results suggest that replacement of these two functional BrAOP2 genes with non-functional alleles has the potential for producing improved Brassica crops with enriched beneficial glucoraphanin content.

Keywords: Brassica rapa, glucosinolate, glucoraphanin, BrAOP2, Marker-assisted backcrossing

\section{INTRODUCTION}

Glucosinolates are a group of specialized secondary metabolites which are rich in nitrogen and sulfur in the order Brassicales (Halkier and Gershenzon, 2006; Sønderby et al., 2010). Glucosinolates and their hydrolytic products are well-known for their bioactivities such as, fungicidal, bactericidal, and cancer-preventive attributes (Fahey et al., 2002; Bones and Rossiter, 2006; Zhang et al., 2006; Clay et al., 2009; Gimsing and Kirkegaard, 2009). For human and animal consumption, some glucosinolates are beneficial while others are detrimental. For example, sulforaphane, the hydrolysis product of glucoraphanin, has been reported to possess cancerpreventive attributes because it can modulate phase I and II detoxification enzymes, thereby affecting cancer development (Mithen, 2001; Mithen et al., 2003; Talalay et al., 2007). In contrast, progoitrin is mainly enriched in rapeseed and is anti-nutritional because its breakdown product has toxic effect on animal and human consumption (Griffiths et al., 1998). Since Brassica species encompass many important vegetable, oilseed, and fodder crops, it is desirable to increase beneficial glucosinolate (glucoraphanin) and reduce the detrimental glucosinolate (progitrin) in Brassica crops to improve their economic and nutritional values and further enhance the potency of their anticancer attributes. 
Biosynthesis of glucosinolates is rather complex process in Arabidopsis and more than 50 genes are involved in, including three major steps: side chain elongation core structure modification, and side chain modification (Kliebenstein et al., 2005; Halkier and Gershenzon, 2006; Sønderby et al., 2010; Li et al., 2011; Redovniković et al., 2012). Compared with Arabidopsis, glucosinolate biosynthesis in Brassica species is more complex and 102 orthologous glucosinolate-related genes and 105 glucosinolate-related genes were identified in B. rapa and $B$. oleracea using comparative genomic analysis, respectively Wang H. et al., 2011; Liu et al., 2014). This is because the Brassica genome experienced the whole genome triplication and chromosomal rearrangements since its divergence from Arabidopsis.

The structural diversity of glucosinlates is due to variation in side chain length and secondary modification (Kliebenstein et al., 2001a; Halkier and Gershenzon, 2006). The AOP family of genes including $A O P 1, A O P 2$, and $A O P 3$ are mainly responsible for secondary modification of the side chain (Hall et al., 2001; Kliebenstein et al., 2001b; Neal et al., 2010). AOP1 gene is reported as the ancestral gene of $A O P 2$ and $A O P 3$, and its function remains unknown (Wittstock and Halkier, 2002; Neal et al., 2010). AOP2 is responsible for the conversion of methylsulfinylalkyl glucosinolates to alkenyl glucosinolates (Kliebenstein et al., 2001b). The step is involved in 4C aliphatic glucosinolate, referring glucoraphanin to gluconapin. $A O P 3$ also show a weak conversion of methylsulfinylalkyl glucosinolate to hydroxyalkyl glucosinolate (Kliebenstein et al., 2001b). Moreover, pervious reports have shown that the accumulation of methylsulfinylalkyl glucosinolates correlate with the expression of a functional $A O P 2$ and $A O P 3$ gene in Arabidopsis (Kliebenstein et al., 2001b). These studies indicate that the expressional and functional changes of $A O P 2$ and $A O P 3$ genes could affect the accumulation of beneficial glucosinolate (glucoraphanin).

The species $B$. rapa encompass a great array of vegetables, such as, Chinese cabbage, pakchoi, mizuna, narinosa, turnip, and many other leafy vegetables (Zhao et al., 2005). They play an important role in daily diet in many regions of the world, particularly in Asia. However, there are only trace amounts or undetectable levels of beneficial glucoraphanin in B. rapa (Padilla et al., 2007; Lou et al., 2008; Kim et al., 2010). In contrast, high concentrations of glucoraphanin have been detected in $B$. oleracea vegetables such as, broccoli, kale, Chinese kale, Brussels sprouts, and purple cauliflower (Fahey et al., 1997; Liu et al., 2012). Further studies have revealed that both $B$. rapa and $B$. oleracea contain three AOP2 homolog genes but no AOP3 homolog genes because Brassica genome experienced the whole genome triplication ( $\mathrm{Li}$ and Quiros, 2003; Wang H. et al., 2011; Liu et al., 2014). In B. oleracea, two BoAOP2 genes (BoAOP2.2 and BoAOP2.3) are non-functional as a result of premature stop mutations, while three BrAOP2 copies are functional in B. rapa Wang $\mathrm{H}$. et al., 2011; Liu et al., 2014; Zhang et al., 2015). This is the generally accepted reason for the abundance of glucoraphanin in $B$. oleracea, but not in $B$. rapa. In addition, silencing $A O P$ genes (GSL-ALK) through RNA interference (RNAi) of $B$. napus and $B$. juncea resulted in accumulation of the content of glucoraphanin, and reduction of detrimental glucosinolate (progitrin) in seeds, respectively (Liu et al., 2012; Augustine and Bisht, 2015). Accordingly, it is possible to increase the beneficial glucoraphanin concentration through genetic manipulation of three BrAOP2 genes in $B$. rapa crops. However, RNAi-mediated gene knocking down or CRISPR/Cas9-mediated gene knocking out remains a challenge since the inefficient Agrobacteria-mediated transformation in B. rapa. Moreover, no mutations of loss-of-function AOP2s have yet been found in $B$. rapa or in any Brassica species other than $B$. oleracea. In this study, we identified natural nonfunctional mutantions of two BrAOP2 genes from "R-O-18" and then performed marker assisted backcross breeding to substitute functional BrAOP2 gene locus in "L58" with non-functional alleles to increase the beneficial glucosinolate (glucoraphanin) in $B$. rapa. The advanced backcross progenies carrying nonfunctional BrAOP2 gene loci were screened with gene specific markers and analyzed for glucosinolate profile and content. Our findings have potential applications in producing glucoraphaninenriched B. rapa crops.

\section{MATERIALS AND METHODS}

\section{Plant Materials for Glucosinolate Analysis}

In the current study, we grew $70 \mathrm{~B}$. rapa accessions (Table S1) with various morphological types during autumn 2014. These accessions included the following morphotypes: ssp. pekinensis (Chinese cabbage), ssp. chinensis (Pakchoi), ssp. rapifera (Turnip), ssp. trilocularis (Yellow sarson), ssp. Narinosa (Wutacai), ssp. chinensis var. tai-tsai Lin (Taicai), ssp. parachinensis (Caixin), ssp. chinensis var. purpurea Bailey (Zicaitai), ssp. Perviridis (Komatsuna), ssp. nipposinica (Mizuna), ssp. broccoletto (Broccoletto), and ssp. Oleifera (Oil).

For all experiments, seeds were first planted in seedling trays. After 20 days, the seedlings were transplanted to larger trays in a greenhouse or field. The youngest leaves of each plant were collected at the rosette stage, immediately frozen in liquid nitrogen and stored in $-80^{\circ} \mathrm{C}$ freezers until freezedried with a vacuum freeze dryer. $200 \mathrm{mg}$ of freeze-dried sample of each accession was used for glucosinolate extraction and measurement by high performance liquid chromatography (HPLC). Three biological replicates for each accession were analyzed in independent experiments.

\section{Plant Materials for Backcross Breeding Scheme}

The B. rapa "R-O-18" (ssp. trilocularis) containing high content of beneficial glucosinolate (glucoraphanin) was used as the donor parent, and "L58" (ssp. parachinensis) with a lower content of beneficial glucosinolate (glucoraphanin) as the recurrent parent. The two parents were hybridized to produce $F_{1}$, and then backcrossed with "L58" to produce a large $\mathrm{BC}_{1}$ population. In the $\mathrm{BC}_{1}$ population, individual plants with heterozygous locus of $B r A O P 2.2$ and $B r A O P 2.3$ was identified for further screening (foreground selection). Then, the individual line with the highest recovery rates was selected with the markers distributed in 10 chromosomes (background selection). When we selected the 
indidual plant $\mathrm{BC}_{1}-018$ with the highest recovery rates from $\mathrm{BC}_{1}$ generation, the tissue culture techniques was used for rapid propagation to make sure we could obtain adequate next generation seeds.

In the $\mathrm{BC}_{2}$ generation, the same method was employed to select the individual lines with the highest recovery rates. Selected $\mathrm{BC}_{2}$ plants were self-pollinated for selection of homozygous loci. These selective $\mathrm{BC}_{2} \mathrm{~S}_{1}$ were again self-pollinated to produce $\mathrm{BC}_{2} \mathrm{~S}_{2}$ for further analysis (Figure $\mathrm{S} 1$ ). All crosses were performed in a greenhouse at the Chinese Academy of Agricultural Sciences (Beijing, China).

\section{Development of Functional Marker of BrAOP2.2 and BrAOP2.3}

The SNP C/T $(+499)$ of BrAOP2.2 was converted to KASP assays following instruction from the manufacturer's instructions (http://www.lgcgroup.com/LGCGroup/media/PDFs/Products/ Genotyping/KASP-genotyping-chemistry-User-guide.pdf).

Primer sequences are listed in Table S2.

In this study, we used $5 \mu \mathrm{l}$ KASP assay polymerase chain reaction (PCR) mix, which includes $2.5 \mu$ l of $2 \times$ KASP Master mix (LGC Genomics, Beverly, MA, USA) of primer assay mix and $2.5 \mu \mathrm{l}$ genomic DNA at a concentration of $15 \mathrm{ng} / \mu \mathrm{l}$. The initial PCR mix was performed in a Gene Amp PCR System 9700 (Applied Biosystems, Foster City, CA, USA). The postPCR fluorescent endpoint readings were carried out using an ABI 7900HT RealTime PCR System (Applied Biosystems, Foster City, CA, USA). The PCR conditions were determined according to the manufacturer's instructions (http://www. lgcgroup.com/LGCGroup/media/PDFs/Products/Genotyping/ KASP-genotyping-chemistry-User-guide.pdf).

The insert sequence $(+788)$ of BrAOP2.3 was verified through InDel assays. The PCR was conducted using the specific primer (Table S2) and the PCR products were resolved on $1.5 \%$ agarose gels.

The KASP assays and InDel assays were used to screen and select in the marker-assisted selection.

\section{Molecular Marker Analysis}

Marker-assisted foreground selection of BrAOP2.2 and $B r A O P 2.3$ in backcross progenies were performed using KASP assays and InDel assays, respectively. For marker-assisted background selection, InDel markers were used to calculate the recovery rates of segregants and to select the individual plants with the closest genetic background to the recurrent parent. The InDel primers come from a published linkage map based on an "L58" × "R-O-18" RIL population (Sun et al., 2016). Using the combination of a genetic and a physical map, a total of 100 InDel markers evenly distributed from 10 chromosomes were selected in the $\mathrm{BC}_{1}$ generation and $33 \mathrm{InDel}$ markers were used in the $\mathrm{BC}_{2}$ generation (Figure S2; Table S3).

\section{Leaf Glucosinolate Measurement by HPLC Analysis}

Glucosinolate profiles of $70 \mathrm{~B}$. rapa accessions were determined by HPLC as described by $\mathrm{He}$ et al. (2002) with minor modifications. The desulfo glucosinolates were verified based on a comparison of UV absorption spectra and retention times (Brown et al., 2003). The concentration of glucosinolate was calculated with an internal standard.

\section{Enzyme Assays of BrAOP2 Protein}

The full-length cDNA of BrAOP2.1, BrAOP2.2, and BrAOP2.3 in "R-O-18" were ligated into the pET32a (Novagen, Madison, WI, USA) vector system. The recombinant plasmids were expressed in E. coli Transetta (TransGen Biotech, Beijing, China) induced by $0.5 \mathrm{mM}$ IPTG at $16^{\circ} \mathrm{C}$ for $12-14 \mathrm{~h}$. The crude protein was purified with BugBuster ${ }^{\circledR}$ Ni-NTA His Bind Purification Kit following the manufacturer's instructions (Novagen, EMD Chemicals, CA, USA). The purified protein was confirmed using SDS-PAGE analysis, and then was used for enzyme activity assays as described by Zhang et al. (2015).

\section{Statistical Analysis}

Multiple comparisons were used to analyze the variation of glucoraphanin content from advanced backcross progenies (Figure 4) using one-way ANOVA with Tukey post-hoc test ( $P$ $<0.05)$ by SPSS v.19.0 software.

\section{RESULTS}

\section{Glucosinolate Analysis in B. rapa}

We analyzed glucosinolate from a collection of $70 \mathrm{~B}$. rapa accessions, representing 10 morphotypes including Chinese cabbage, Caixin, Komatsuna, Pakchoi, Mizuna, Taicai, Turnip, Wutacai, Yellow sarson, and Zicaitai using HPLC (Table S1). A total of eight types of glucosinolates were detected including four aliphatic glucosinolates (progoitrin, gluconapin, glucobrassicanapin, glucoraphanin) and four indolic glucosinolates (glucobrassicin, 4-methoxyglucobrassicin, neoglucobrassicin, 4-hydroxyglucobrassicin; Table 1). Of these, aliphatic glucosinolate gluconapin and glucobrassicanapin were detected in almost all of the accessions and represented the major glucosinolates, which is consistent with previous studies (Padilla et al., 2007; Kim et al., 2010). The highest total glucosinolate contents (16.22-48.87 $\left.\mu \mathrm{mol} \mathrm{g}^{-1} \mathrm{DW}\right)$ and major aliphatic glucosinolates (gluconapin and glucobrassicanapin) were observed in Turnip. A slightly higher content of indolic glucosinolates was found in Chinese cabbage compared with other types. Importantly, out of eight glucosinolates, seven were identified in all accessions except the beneficial glucosinolate (glucoraphanin) was only found in Yellow sarson.

\section{Sequence Analysis of Three BrAOP2 Genes in Yellow Sarson}

To investigate whether the high accumulation of glucoraphanin in Yellow sarson is due to the non-functional mutation of BrAOP2 genes, we investigated sequence variations of all three BrAOP2 genes in Yellow sarson type "R-O-18" which contains a high glucoraphanin content $\left(3.006 \pm 0.40 \mu \mathrm{mol} \mathrm{g}^{-1}\right.$ DW) compared with those in Chines cabbage "Chiifu-401/42" with undetectable glucoraphanin. As a result, in the coding region of BrAOP2.1, two synonymous substitutions, two nonsynonymous substitutions, a 3-bp deletion, and a 3-bp insertion 
TABLE 1 | Glucosinolates in leaves of B. rapa $\left(\mu \mathrm{mol} \mathrm{g}^{-1} \mathrm{DW}\right)$.

\begin{tabular}{|c|c|c|c|c|c|c|c|c|c|c|}
\hline \multirow[t]{2}{*}{ Type } & \multicolumn{4}{|c|}{ Aliphatic GSLs } & \multirow{2}{*}{$\begin{array}{c}\text { Total } \\
\text { aliphatic } \\
\text { GSLs }\end{array}$} & \multicolumn{4}{|c|}{ Indolic GSLs } & \multirow{2}{*}{$\begin{array}{l}\text { Total } \\
\text { indolic } \\
\text { GSLs }\end{array}$} \\
\hline & PRO & NAP & GBN & GRA & & GBC & $4 \mathrm{ME}$ & NEO & $40 \mathrm{OH}$ & \\
\hline $\begin{array}{l}\text { Chinese } \\
\text { cabbage }\end{array}$ & $1.21 \pm 0.77$ & $0.91 \pm 1.51$ & $1.16 \pm 1.45$ & nd & $3.28 \pm 2.91$ & $0.98 \pm 0.61$ & $0.37 \pm 0.19$ & $0.30 \pm 0.28$ & $0.11 \pm 0.10$ & $1.76 \pm 0.71$ \\
\hline Caixin & $1.02 \pm 1.53$ & $5.64 \pm 5.20$ & $0.74 \pm 0.40$ & nd & $7.39 \pm 6.84$ & $0.25 \pm 0.13$ & $0.12 \pm 0.05$ & $0.18 \pm 0.16$ & $0.05 \pm 0.03$ & $0.61 \pm 0.32$ \\
\hline Mizuna & $0.37 \pm 0.04$ & $18.50 \pm 8.00$ & $1.19 \pm 0.11$ & nd & $20.06 \pm 8.27$ & $0.39 \pm 0.12$ & $0.17 \pm 0.09$ & $0.29 \pm 0.18$ & $0.08 \pm 0.03$ & $0.92 \pm 0.42$ \\
\hline Taicai & $1.63 \pm 0.79$ & $3.11 \pm 1.29$ & $3.64 \pm 1.43$ & nd & $8.38 \pm 3.05$ & $0.48 \pm 0.27$ & $0.10 \pm 0.03$ & $0.56 \pm 0.32$ & $0.19 \pm 0.09$ & $1.32 \pm 0.50$ \\
\hline Turnip & $0.44 \pm 0.25$ & $24.58 \pm 10.70$ & $7.49 \pm 3.73$ & nd & $32.51 \pm 13.38$ & $0.46 \pm 0.06$ & $0.15 \pm 0.12$ & $0.30 \pm 0.07$ & $0.13 \pm 0.03$ & $1.04 \pm 0.10$ \\
\hline Wutacai & $0.71 \pm 0.07$ & $2.35 \pm 2.78$ & $2.02 \pm 2.52$ & nd & $5.09 \pm 5.37$ & $0.71 \pm 0.01$ & $0.10 \pm 0.01$ & $1.01 \pm 1.07$ & $0.07 \pm 0.02$ & $1.90 \pm 1.06$ \\
\hline $\begin{array}{l}\text { Yellow } \\
\text { sarson }\end{array}$ & $0.60 \pm 0.09$ & $22.96 \pm 0.35$ & $0.22 \pm 0.15$ & $2.87 \pm 1.82$ & $26.66 \pm 2.04$ & $0.09 \pm 0.03$ & $0.07 \pm 0.01$ & $0.14 \pm 0.06$ & $0.02 \pm 0.01$ & $0.32 \pm 0.06$ \\
\hline
\end{tabular}

PRO, progoitrin; NAP, gluconapin; GBN, glucobrassicanapin; GRA, glucoraphanin; GBC, glucobrassicin; 4ME, 4-methoxyglucobrassicin; NEO, neoglucobrassicin; 4OH, 4hydroxyglucobrassicin. GSLs, glucosinolates. nd, not detected. Each value is the mean \pm standard deviation.

were detected (Figure 1; Figure S3A). Although the C/A SNP at position +587 and $\mathrm{G} / \mathrm{C}$ SNP at position $+1,261$ resulted in an amino acid change of $\mathrm{T} / \mathrm{N}$ and $\mathrm{E} / \mathrm{Q}$, respectively, the change in $\mathrm{T} / \mathrm{N}$ affected neither the amino acid R-chain charge nor the amino acid polarity and the change in E/Q did not belong to highly conserved amino acid residues, which are crucial for enzymatic activity in BrAOP2 (Zhang et al., 2015). Moreover, the 3-bp insertion $(+564)$ and the 3-bp deletion $(+604)$ resulted in a deletion and an insertion of amino acid, respectively, which is unlikely to have resulted in the functional change.

Interestingly, the $\mathrm{B} r A O P 2.2$ gene sequence exhibited complete identity between the "R-O-18" and "Chiifu-401/42" with the exception of C/T SNP in exon 2 at the gene position +499 and G/A SNP at position +1128 (Figure 1; Figure S3B). The G/A SNP at position $+1,128$ resulted in a synonymous mutant, while the C/T SNP at position +499 led to production of a premature termination codon mutation.

Sequencing of the BrAOP2.3 gene in "R-O-18" revealed four synonymous substitutions, four non-synonymous substitutions, and a 209-bp insertion in exon 2 at position +788 in the coding region (Figure 1; Figure S3C). Of these variations, the 209-bp insertion drew our attention because it resulted in a frame shift and generated a premature translation termination product.

Taken together, the sequence variation of BrAOP2.2 and BrAOP2.3 in "R-O-18" resulted in the premature translation termination product which most likely led to loss-function of the BrAOP2.2 and BrAOP2.3 genes, while the nucleotide variation of BrAOP2.1 is unlikely to have altered the protein function in "R-O-18."

\section{The BrAOP2.2 and BrAOP2.3 Gene in Yellow Sarson was Non-functional}

Our previous study demonstrated that all three BrAOP2 proteins in "Chiifu-401/42" could catalyze the conversion of

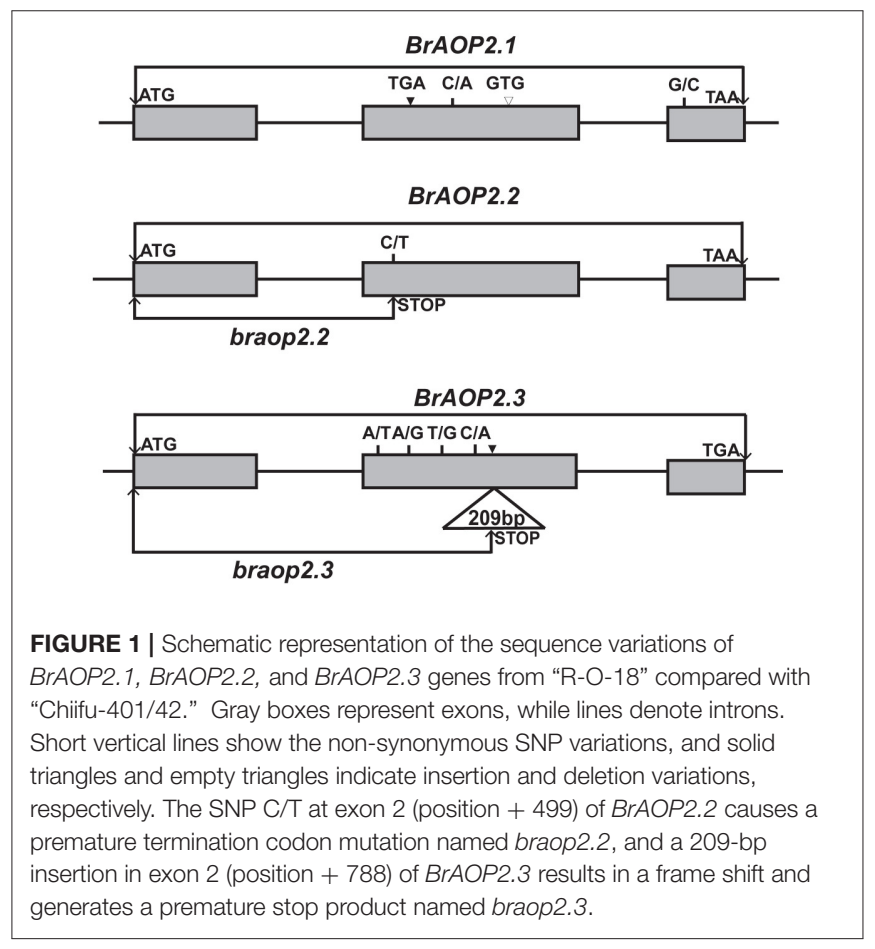

glucoraphanin to gluconapin in vivo and in vitro (Zhang et al., 2015). To further determine whether the BrAOP2.2 and $B r A O P 2.3$ in "R-O-18" are non-functional while BrAOP2.1 is functional as predicted above, we analyzed the in vitro enzymatic activity of three BrAOP2 proteins in "R-O-18". The full-length cDNA of the three BrAOP2 genes were cloned from "R-O18" and heterologously expressed in Escherichia coli. All the purified proteins (Figure S4) were incubated with the substrate glucoraphanin and we then tested their catalyze activity using 
enzymatic in vitro assays as described in Zhang et al. (2015). As shown in Figure 2, glucoraphanin can be converted to gluconapin by BrAOP2.1 protein. However, BrAOP2.2 and BrAOP2.3 protein were unable to catalyze glucoraphanin to gluconapin. The results indicate that BrAOP2.2 and BrAOP2.3 protein abolished catalysis activity, while BrAOP2.1 protein retained catalysis activity. This result was consistent with our prediction from the gene sequence analysis.

\section{Replacement of Non-functional braop2.2 and braop2.3 Increases the Glucoraphanin Content in $B$. rapa}

To enrich accumulation of glucoraphanin in $B$. rapa, the non-functional BrAOP2 genes were introgressed using marker-assisted backcrossing (MAB) strategy to a desirable $B$. rapa variety without glucoraphanin to replace the functional alleles. For this purpose, "R-O-18" containing high glucoraphanin content was used as a donor for the non-functional braop2.2 and braop2.3 allele, and "L58" containing undetectable or trace amounts of glucoraphanin harboring functional $\mathrm{BrAOP} 2.2$ and $\mathrm{BrAOP} 2.3$ which have the same coding sequences with "Chiifu-401/42" was used as a recurrent parent. The specific KASP marker for the BrAOP2.2 gene (BrAOP2.2_KASP) and InDel marker for the BrAOP2.3 gene (BrAOP2.3_InDel) were used to screen the heterozygous alleles (BrAOP2.2/braop2.2, BrAOP2.3/braop2.3) from the backcross populations (Figure S5). A total of 424 $\mathrm{BC}_{1}$ plants derived from "L58" $\times$ "R-O-18" were used for the first round of foreground selection (Figure S1) and 192 plants showed the homozygous genotype (BrAOP2.2/BrAOP2.2) for the BrAOP2.2_KASP marker, whereas 232 plants showed the heterozygous genotype. Then the 232 heterozygous plants at theBrAOP2.2locus were used for the selection of BrAOP2.3_InDel maker (Table S2). As a result, 112 plants showed the heterozygous genotype of these two alleles and then were used for subsequent background selection (Table S4).

For background selection, the polymorphic InDel markers between parental lines "L58" and "R-O-18" were derived from the previous linkage map based on "L58" $\times$ "R-O-18" RIL population, which comprised a total of 372 InDel markers with a total length of $968.9 \mathrm{cM}$ (Sun et al., 2016). Out of 372 InDel markers, 100 InDel markers were selected for background selection based on a physical map and linkage map, and then the recovery rates of the recurrent parent were calculated (Figure S2). The plant $\left(\mathrm{BC}_{1}-018\right)$ with an $83.5 \%$ recovery rate were selected and crossed with the recurrent parent "L58" to produce $\mathrm{BC}_{2}$ plants (Figure 3 ). In total, $242 \mathrm{BC}_{2}$ plants were obtained and used for the second round of foreground selection. Among these plants, 112 plants showed the BrAOP2.2/BrAOP2.2 genotype, whereas 130 showed the heterozygous genotype (BrAOP2.2/braop2.2). Then the 130 plants with the heterozygous genotype were retained for the selection of BrAOP2.3_InDel maker. A total of 64 plants harboring these two heterozygous alleles were used for background selection with 33 InDel markers, which were heterozygous in $\mathrm{BC}_{1}-018$. The plant $\mathrm{BC}_{2}-227$ with highest recovery rates (94\%) was selected and selfed to produce $\mathrm{BC}_{2} \mathrm{~S}_{1}$ (Figure S1;Table S4).

The homozygous alleles of braop2.2 and braop2.3 were screened from $\mathrm{BC}_{2} \mathrm{~S}_{1}$, and four types of homozygous combination alleles were obtained. These $\mathrm{BC}_{2} \mathrm{~S}_{1}$ plants were again selfed and generated $\mathrm{BC}_{2} \mathrm{~S}_{2}$ plants (Figure $\mathrm{S} 1$ ). Of these, $\mathrm{BC}_{2} \mathrm{~S}_{2}$ plants with homozygous combination were selected and their leaves were harvested to perform the glucosinolate analysis using HPLC. As shown in Figure 4A, individual lines with introgression of both braop 2.2 and braop 2.3 significantly increased the beneficial glucoraphanin concentration by 18 times compared with the recurrent parent "L58". Further, significant reduction in the gluconapin was observed in the lines with braop2.2 and braop2.3 than recurrent parent "L58" (Figure 4B). However, the backcrossing progenies with introgression of single braop2.2 or braop2.3 did not change the levels of glucoraphanin or gluconapin. These results demonstrate that replacement of non-functional braop2.2 and braop2.3 can increase glucoraphanin accumulation content in B. rapa.

\section{DISCUSSION}

Glucosinolate biosynthesis is a rather complex process involved in more than 50 genes, forming various glucosinolates products from different precursor amino acid in Arabidopsis (Sønderby et al., 2010). Although both Brassica species and Arabidopsis belong to the Brassicaceae family, Brassica species experienced the event of whole genome duplication (WGD) from 10 million years ago, resulting in the expansion of gene number and gene divergence (Wang X. et al., 2011; Cheng et al., 2012). This caused the glucosinolate biosynthesis of Brassica species to be more complex than that of Arabidopsis.

Since all Brassica species undergoes gene duplication compared with Arabidopsis, it is difficult to screen the nonfunctional mutants with desired traits in Brassica species (Liu et al., 2012); that is, it is not easy to obtain loss-function of all functional redundancy genes. The RNAi or CRISPR/Cas9 systems have been demonstrated to be effective methods to knock down or knock out several homologous genes with sequence similarity to create the mutant with desired trait. To date, the RNAi has been successfully used to silence all the AOP2 (GSL-ALK) genes, which resulted in the increase of beneficial glucosinolate glucoraphanin in $B$. napus and $B$. juncea (Liu et al., 2012; Augustine and Bisht, 2015). However, it remains challenging to increase the beneficial glucoraphanin content in $B$. rapa through knocking down or knocking out three $B r A O P 2$ genes using the RNAi or CRISPR/Cas9 strategies. This is because B. rapa is recalcitrant to Agrobacterium-mediated transformation (Vanjildorj et al., 2009).

The MAB method uses molecular markers to accelerate the selection of individuals containing the target locus from the donor line and high recurrence of the recipient background (Hospital and Charcosset, 1997). Compared with conventional backcrossing, MAB can save considerable time and labor for breeding new cultivars with desired traits. Therefore, pyramiding non-functional BrAOP2 alleles using MAB seems an appropriate 


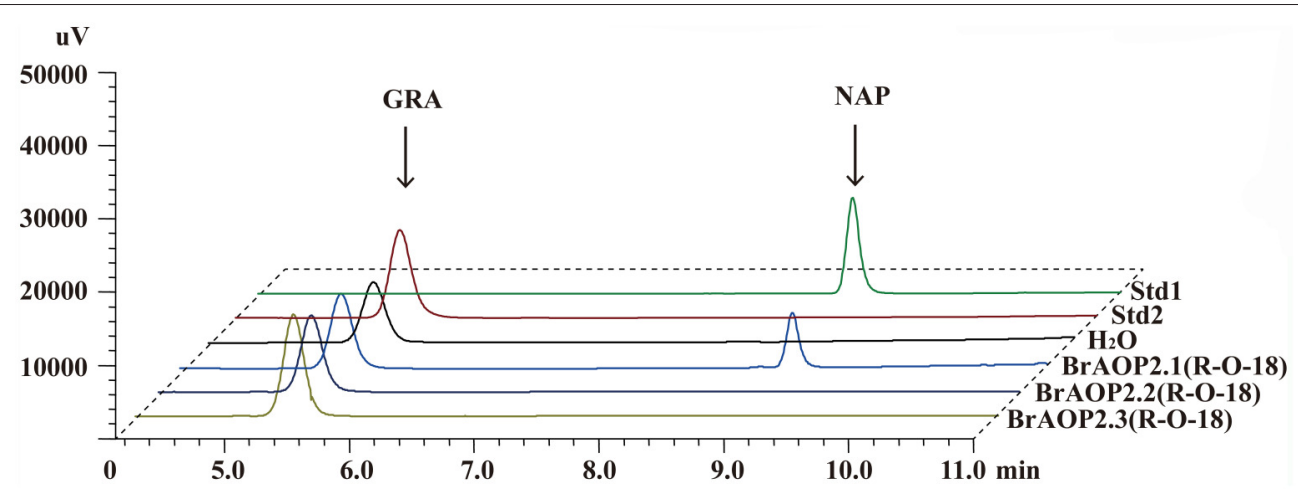

FIGURE 2 | HPLC analyses of enzymatic activity of three BrAOP2s of R-O-18 in vitro. Std1 and Std 2 indicate desulfatedgluconapin (NAP) standard and desulfated glucoraphanin (GRA) standard, respectively. Conversion of GRA to NAP was catalyzed by BrAOP2.1, but not by BrAOP2.2 or BrAOP2.3 protein. $\mathrm{H}_{2} \mathrm{O}$ shows as the negative control.

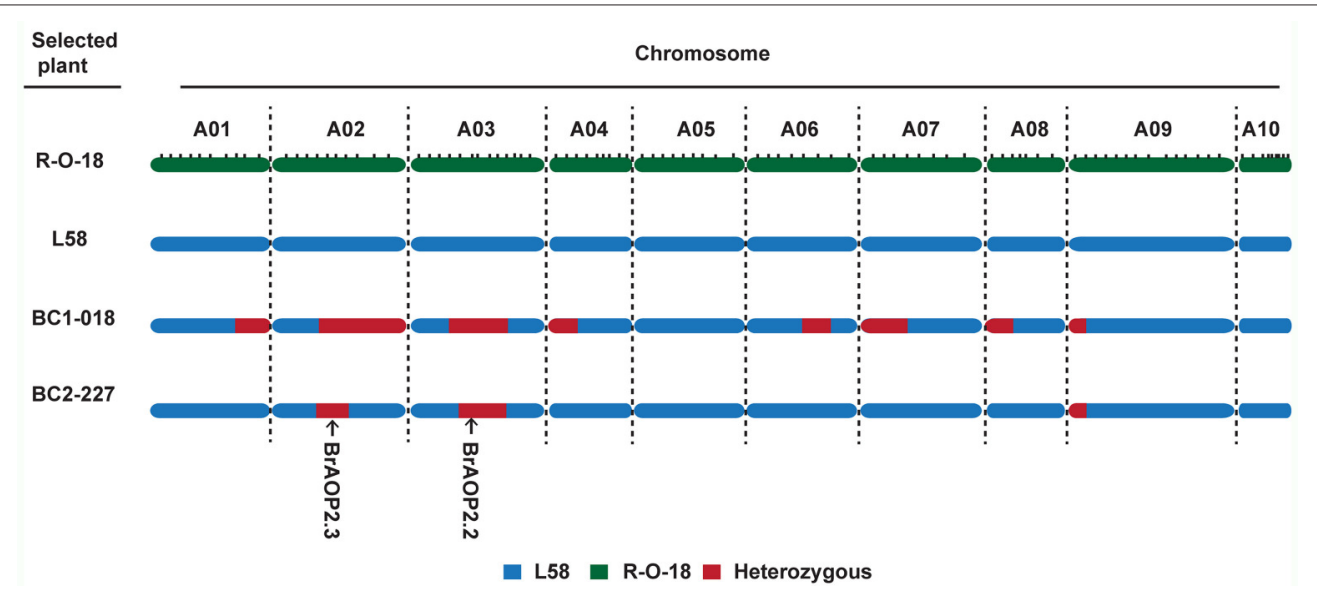

FIGURE 3 | Graphical genotype of the selected $\mathrm{BC}_{1}$ and $\mathrm{BC}_{2}$ plants. The green region represents segments from the recurrent parent "L58," the blue region represents segments from donor parent "R-O-18," and the dark red region represents heterozygous segments.
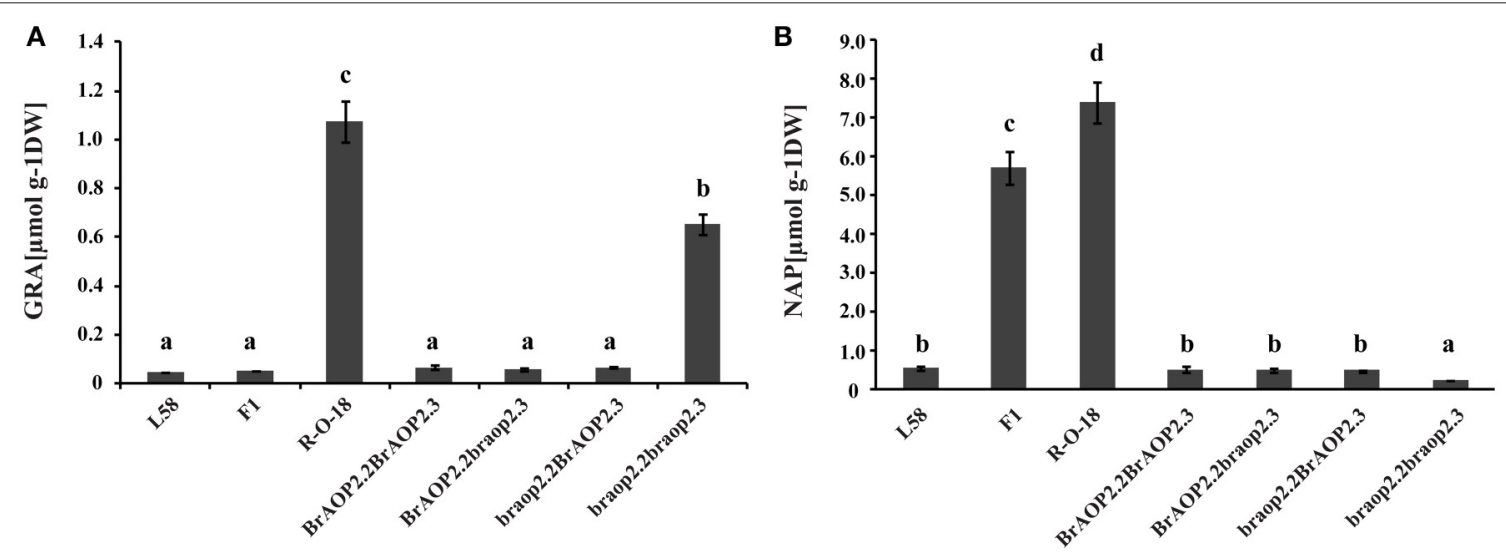

FIGURE 4 | Glucoraphanin concentrations (A) and gluconapin concentration (B) in leaves of parental lines, F1 line and advanced backcross progenies. Data are shown as mean $\pm S D$ obtained from at least two biological replicates. Different letters indicate significant difference between genotypes (Tukey, $P<0.05$ ). 
alternative method to replace all the functional $B r A O P 2$ genes in B. rapa. However, so far the non-functional $A O P 2$ alleles have only been found in some $B$. oleracea. Li and Quiros (2003) identified a 2 bp deletion in exon 2 of BoGSL-ALK (BoAOP2) in broccoli, which was demonstrated to abolish its function. Liu et al. (2014) identified two BoAOP2 genes that were non-functional owing of the presence of a premature stop codon, which was suggested to contribute to the accumulation of glucoraphanin.

Although $B$. oleracea $(n=9, \mathrm{CC})$ is a close relative of $B$. rapa ( $n=10, \mathrm{AA}$ ), the non-functional mutation of BoAOP2 genes is difficult to use to replace the functional alleles of $B$. rapa by the interspecific hybridization between $B$. rapa and $B$. oleracea. In this case, the purpose of our current work was to identify mutants of non-functional AOP2 genes from $B$. rapa accessions and then use the MAB method to pyramid all the non-functional AOP2 genes into a target material and replace the functional alleles, thus inhibiting the conversion of glucoraphanin to gluconapin and increasing the glucoraphanin accumulation. However, we only identified natural mutant of non-functional BrAOP2.2 and $B r A O P 2.3$ allele with premature termination in the Yellow sarson type containing high glucoraphanin, but not the non-functional BrAOP2.1 allele mutant.

In order to introduce the non-functional $B r A O P 2.2$ and BrAOP2.3 gene to the recurrent parent "L58" with undetectable glucoraphanin and functional BrAOP2.2 and BrAOP2.3 gene to increase the glucoraphanin concentration using MAB. 100 polymorphism inDel markers between "L58" and "R-O-18" were used for background selection, and the average marker density was $\sim 9.68 \mathrm{cM}$. Previous report has shown that the density of markers for background selection were at least one every $10 \mathrm{cM}$ (Herzog and Frisch, 2011). Therefore, $100 \mathrm{inDel}$ markers were sufficient for MAB in our population.

The backcross progenies with introgression of both non-functional BrAOP2.2(braop2.2) and BrAOP2.3(braop2.3) alleles significantly increased the glucoraphanin accumulation compared with the recurrent parent, while replacement or introgression of a single braop2.2 or braop2.3 locus did not change the glucoraphanin content. These results demonstrated that loss-of-function of only one copy of BrAOP2 did not affect their function of conversion of glucoraphanin to gluconapin because of the gene function redundancy. Accordingly, if all three

\section{REFERENCES}

Augustine, R., and Bisht, N. C. (2015). Biofortification of oilseed Brassica juncea with the anti-cancer compound glucoraphanin by suppressing GSL-ALK gene family. Sci. Rep. 5:18005. doi: 10.1038/srep18005

Bones, A. M., and Rossiter, J. T. (2006). The enzymic and chemically induced decomposition of glucosinolates. Cheminform 67, 1053-1067. doi: 10.1016/j. phytochem.2006.02.024

Brown, P. D., Tokuhisa, J. G., Reichelt, M., and Gershenzon, J. (2003). Variation of glucosinolate accumulation among different organs and developmental stages of Arabidopsis thaliana. Phytochemistry 62, 471-481. doi: 10.1016/S0031-9422(02)00549-6

Cheng, F., Wu, J., Fang, L., Sun, S., Liu, B., Lin, K., et al. (2012). Biased gene fractionation and dominant gene expression among the provided $B r A O P 2$ genes were replaced by non-functional alleles, the plants would probably increase glucoraphanin accumulation as a result of the lower conversion of glucoraphanin to gluconapin relative to plants containing two non-functional $B r A O P 2$. However, so far we have not identified the natural mutant of the BrAOP2.1 gene in our collection of $B$. rapa accessions. Therefore, the non-functional mutant of BrAOP2.1 should be screened, which could be achieved using the TILLING approach in a future study. In addition, we also noticed that introgression of two non-functional BrAOP2.2 and BrAOP2.3 leads to the increase of the glucoraphanin content without causing any obvious morphological appearance changes. These findings have profound implications for improvement of glucoraphanin-enriched $B$. rapa vegetable and oilseed crops, and the backcross progenies with high glucoraphanin content achieved in this study could be used to produce glucoraphanin-enriched B. rapa vegetables.

\section{AUTHOR CONTRIBUTIONS}

ZL, JL, SZ, JZ, and FC performed the experiments and analyzed the data. ZL, JL, and XW wrote the manuscript. JW, WY, and $\mathrm{XW}$ conceived the project, designed the research and revised the paper.

\section{FUNDING}

This work is funded by the National Program on Key Research Project (2016YFD0100506); the 973 program (2013CB127000); the National Natural Science Foundation of China (31301784, 31630068) and National Science and Technology Ministry (2014BAD01B09); the Science and Technology Innovation Program of the Chinese Academy of Agricultural Sciences; CAAS-XTCX2016009; the Key Laboratory of Biology and Genetic Improvement of Horticultural Crops, Ministry of Agriculture, P. R. China.

\section{SUPPLEMENTARY MATERIAL}

The Supplementary Material for this article can be found online at: http://journal.frontiersin.org/article/10.3389/fpls.2017. 01329/full\#supplementary-material subgenomes of Brassica rapa. PLoS ONE7:e36442. doi: 10.1371/journal.pone.00 36442

Clay, N. K., Adio, A. M., Denoux, C., Jander, G., and Ausubel, F. M. (2009). Glucosinolate metabolites required for an Arabidopsis innate immune response. Science 323:95. doi: 10.1126/science.1164627

Fahey, J. W., Haristoy, X., Dolan, P. M., Kensler, T. W., Scholtus, I., Stephenson, K. K., et al. (2002). Sulforaphane inhibits extracellular, intracellular, and antibiotic-resistant strains of Helicobacter pylori and prevents benzo[a]pyreneinduced stomach tumors. Proc. Natl. Acad. Sci. U.S.A. 99, 7610-7615. doi: 10.1073/pnas.112203099

Fahey, J. W., Zhang, Y., and Talalay, P. (1997). Broccoli sprouts: an exceptionally rich source of inducers of enzymes that protect against chemical carcinogens. Proc. Natl. Acad. Sci. U.S.A. 94, 10367-10372. doi: 10.1073/pnas.94.19. 10367 
Gimsing, A. L., and Kirkegaard, J. A. (2009). Glucosinolates and biofumigation: fate of glucosinolates and their hydrolysis products in soil. Phytochem. Rev. 8, 299-310. doi: 10.1007/s11101-008-9105-5

Griffiths, D., Birch, A., and Hillman, J. (1998). Antinutritional compounds in the brasi analysis, biosynthesis, chemistry and dietary effects. J. Hortic. Sci. Biotechnol. 73, 1-18. doi: 10.1080/14620316.1998.11510937

Halkier, B. A., and Gershenzon, J. (2006). Biology and biochemistry of glucosinolates. Annu. Rev. Plant Biol. 57, 303-333. doi: 10.1146/annurev.arplant.57.032905.105228

Hall, C., McCallum, D., Prescott, A., and Mithen, R. (2001). Biochemical genetics of glucosinolate modification in Arabidopsis and Brassica. Theor. Appl. Genet. 102, 369-374. doi: 10.1007/s001220051655

He, H., Chen, H., and Schnitzler, W. H. (2002). Glucosinolate composition and contents in brassica vegetables. Sci. Agric. Sin. 35, 192-197. doi: 10.3321/j. issn:0578-1752.2002.02.015

Herzog, E., and Frisch, M. (2011). Selection strategies for marker-assisted backcrossing with high-throughput marker systems. Theor. Appl. Genet. 123, 251-260. doi: 10.1007/s00122-011-1581-0

Hospital, F., and Charcosset, A. (1997). Marker-assisted introgression of quantitative trait loci. Genetics 147, 1469-1485.

Kim, J. K., Chu, S. M., Kim, S. J., Lee, D. J., Lee, S. Y., Lim, S. H., et al. (2010). Variation of glucosinolates in vegetable crops of Brassica rapa L. ssp. pekinensis. Food Chem. 119, 423-428. doi: 10.1016/j.foodchem.2009.08.051

Kliebenstein, D. J., Kroymann, J., Brown, P., Figuth, A., Pedersen, D., Gershenzon, J., et al. (2001a). Genetic control of natural variation in Arabidopsis glucosinolate accumulation. Plant Physiol. 126, 811-825. doi: $10.1104 / \mathrm{pp} .126 .2 .811$

Kliebenstein, D. J., Kroymann, J., and Mitchell-Olds, T. (2005). The glucosinolatemyrosinase system in an ecological and evolutionary context. Curr.Opin. Plant Biol. 8, 264-271. doi: 10.1016/j.pbi.2005.03.002

Kliebenstein, D. J., Lambrix, V. M., Reichelt, M., Gershenzon, J., and Mitchell-Olds, T. (2001b). Gene duplication in the diversification of secondary metabolism: tandem 2-oxoglutarate-dependent dioxygenases control glucosinolate biosynthesis in Arabidopsis. Plant Cell 13, 681-693. doi: $10.1105 /$ tpc.13.3.681

Li, G., and Quiros, C. (2003). In planta side-chain glucosinolate modification in Arabidopsis by introduction of dioxygenase Brassica homolog BoGSL-ALK. Theor. Appl. Genet. 106, 1116-1121. doi: 10.1007/s00122-002-1161-4

Li, J., Kristiansen, K. A., Hansen, B. G., and Halkier, B. A. (2011). Cellular and subcellular localization of flavin-monooxygenases involved in glucosinolate biosynthesis. J. Exp. Bot. 62, 1337-1346. doi: 10.1093/jxb/erq369

Liu, S., Liu, Y., Yang, X., Tong, C., Edwards, D., Parkin, I. A., et al. (2014). The Brassica oleracea genome reveals the asymmetrical evolution of polyploid genomes. Nat. Commun. 5:3930. doi: 10.1038/ncomms4930

Liu, Z., Hirani, A. H., McVetty, P. B., Daayf, F., Quiros, C. F., and Li, G. (2012). Reducing progoitrin and enriching glucoraphanin in Braasica napus seeds through silencing of the GSL-ALK gene family. Plant Mol. Biol. 79, 179-189. doi: 10.1007/s11103-012-9905-2

Lou, P., Zhao, J., He, H., Hanhart, C., Carpio, D. P. D., Verkerk, R., et al. (2008). Quantitative trait loci for glucosinolate accumulation in Brassica rapa leaves. New Phytol. 179, 1017-1032. doi: 10.1111/j.1469-8137.2008.02530.x

Mithen, R. (2001). Glucosinolates - biochemistry, genetics and biological activity. Plant Growth Regul. 34, 91-103. doi: 10.1023/A:1013330819778

Mithen, R., Faulkner, K., Magrath, R., Rose, P., Williamson, G., and Marquez, J. (2003). Development of isothiocyanate-enriched broccoli, and its enhanced ability to induce phase 2 detoxification enzymes in mammalian cells. Theor. Appl.Genet. 106, 727-734. doi: 10.1007/s00122-002-1123-x
Neal, C. S., Fredericks, D. P., Griffiths, C. A., and Neale, A. D. (2010). The characterisation of AOP2: a gene associated with the biosynthesis of aliphatic alkenyl glucosinolates in Arabidopsis thaliana. BMC Plant Biol. 10:170. doi: 10.1186/1471-2229-10-170

Padilla, G., Cartea, M. E., Velasco, P., De Haro, A., and Ordas, A. (2007). Variation of glucosinolates in vegetable crops of Brassica rapa. Phytochemistry 68, 536-545. doi: 10.1016/j.phytochem.2006.11.017

Redovniković, I. R., Textor, S., Lisnić, B., and Gershenzon, J. (2012). Expression pattern of the glucosinolate side chain biosynthetic genes MAM1 and MAM3 of Arabidopsis thaliana in different organs and developmental stages. Plant Physiol. Biochem. 53, 77-83. doi: 10.1016/j.plaphy.2012.01.015

Sønderby, I. E., Geu-Flores, F., and Halkier, B. A. (2010). Biosynthesis of glucosinolates gene discovery and beyond. Trends Plant Sci. 15, 283-290. doi: 10.1016/j.tplants.2010.02.005

Sun, Q., Wu, J., Cheng, F., Wang, X., Liang, J., and Shen, S. (2016). QTL mapping of self-compatibility, silique and seeds-associated traits in Brassica rapa. Sci. Agric. Sin. 49, 2449-2458. doi: 10.3864/j.issn.0578-1752.2016.13.001

Talalay, P., Fahey, J. W., Healy, Z. R., Wehage, S. L., Benedict, A. L., Min, C., et al. (2007). Sulforaphane mobilizes cellular defenses that protect skin against damage by UV radiation. Proc. Natl. Acad. Sci. U.S.A. 104, 17500-17505. doi: 10.1073/pnas.0708710104

Vanjildorj, E., Song, S. Y., Yang, Z. H., Choi, J. E., Noh, Y. S., Park, S., et al. (2009). Enhancement of tolerance to soft rot disease in the transgenic Chinese cabbage (Brassica rapa L. ssp. pekinensis) inbred line, Kenshin. Plant Cell Rep. 28, 1581-1591. doi: 10.1007/s00299-009-0757-4

Wang, H., Wu, J., Sun, S., Liu, B., Cheng, F., Sun, R., et al. (2011). Glucosinolate biosynthetic genes in Brassica rapa. Gene 487, 135-142. doi: 10.1016/j.gene.2011.07.021

Wang, X., Wang, H., Wang, J., Sun, R., Wu, J., Liu, S., et al. (2011). The genome of the mesopolyploid crop species Brassica rapa. Nat. Genet. 43, 1035-1039. doi: 10.1038/ng.919

Wittstock, U., and Halkier, B. A. (2002). Glucosinolate research in the Arabidopsis era. Trends Plant Sci. 7, 263-270. doi: 10.1016/S1360-1385(02)02273-2

Zhang, J., Liu, Z., Liang, J., Wu, J., Cheng, F., and Wang, X. (2015). Three genes encoding AOP2, a protein involved in aliphatic glucosinolate biosynthesis, are differentially expressed in Brassica rapa. J. Exp. Bot. 66, 6205-6218. doi: 10.1093/jxb/erv331

Zhang, Z., Ober, J. A., and Kliebenstein, D. J. (2006). The gene controlling the quantitative trait locus EPITHIOSPECIFIER MODIFIER1 alters glucosinolate hydrolysis and insect resistance in Arabidopsis. Plant Cell 18, 1524-1536. doi: $10.1105 /$ tpc. 105.039602

Zhao, J., Wang, X., Deng, B., Lou, P., Wu, J., Sun, R., et al. (2005). Genetic relationships within Brassica rapa as inferred from AFLP fingerprints. Theor. Appl. Genet. 110, 1301-1314. doi: 10.1007/s00122-005-1 967-y

Conflict of Interest Statement: The authors declare that the research was conducted in the absence of any commercial or financial relationships that could be construed as a potential conflict of interest.

Copyright (C) 2017 Liu, Liang, Zheng, Zhang, Wu, Cheng, Yang and Wang. This is an open-access article distributed under the terms of the Creative Commons Attribution License (CC BY). The use, distribution or reproduction in other forums is permitted, provided the original author(s) or licensor are credited and that the original publication in this journal is cited, in accordance with accepted academic practice. No use, distribution or reproduction is permitted which does not comply with these terms. 